\title{
The effects of higher education mergers on the resultant curricula of the combined institutions
}

\author{
MX Mfusi* \\ University of Pretoria
}

\begin{abstract}
Since the dawn of democracy in South Africa (from 1994), the education sector has been haunted by the spirit of change and transformation from the apartheidinfluenced education system to the one that will represent the demographic makeup of this country. As a result of this line of thinking, there has been a policy for all sectors of education - from early childhood development to higher education. Discussion documents have been followed by Green Papers, White Papers and Acts. The higher education sector has been no exception in the situation whereby a flurry of policies have been made, amended and re-amended in order to change the landscape. The latest landmark has been the 'merging' of higher educational institutions and reducing their number from 36 to 21 . This state of affairs has raised many concerns, questions, arguments and debates from the institutions involved, their staff (both academic and non-academic), the entire academic regime, politicians and society in general. When institutions merge, numerous aspects such as the curriculum, efficiency, equity, staffing, students, organisational integration and physical integration effects can be either negatively or positively affected. ${ }^{1}$ This article will focus only on what happens to the curricula of the merged institutions? And what are the effects (either positive or negative) of these mergers on the resultant curricula of the combined institutions? ${ }^{2}$ There are various scenarios whereby the curriculum of one or both institutions could remain unchanged, or the curriculum could be a partial compromise of the new curriculum to reflect both institutions; and a complete integration whereby the curriculum of one of the institutions is completely discarded.
\end{abstract}

\section{RATIONALE OF THE ARTICLE}

The question that this article seeks to unravel is: What happens to the resultant curriculum when institutions merge, each with its own curricula? In other words, does the bringing together of two institutions mean a rationalisation of the curriculum, or at the very least, a use of combined expertise and materials of the two entities to create a single curriculum? The five case studies discussed later in the article spell out three different answers and scenarios to this phenomena. It seems as if in the merging process the curriculum is often treated as secondary to the larger financial and organisational alterations resulting from mergers. In other words, few institutions merge to resolve the curriculum problem. And yet the

M X Mfusi, Faculty of Education, University of Pretoria, Groenkloof Campus, PRETORIA 0001 
curriculum stands at the heart of the teaching and learning transaction in higher education. As Ensor (2002:272) puts it, the issues of knowledge production through research and knowledge reproduction through curriculum and pedagogy have enjoyed far less prominence and attention from the policy-makers and education planners alike since the early 1990s. As I discuss in the following section of the article, this situation has left the merged institutions with no framework or a policy to base their decisions on in as far as the curricular issues are concerned. Hence some institutions have had more to loose than to gain from the merger in as far as the curriculum is concerned. I will draw my examples and illustrations from five 'merger case studies' that unfolded at the beginning of the twenty-first century in South Africa in order to support my argument.

\section{SETTING THE STAGE}

In a few years after the demise of the dominance of the decades-long apartheid education model, the higher education system has undergone a policy-driven restructuring of the higher education sector. The founding policy document on higher education after apartheid is the Report of the National Commission on Higher Education (NCHE) entitled A framework for transformation (1996). In this report, one of some of the imperatives that could build the higher education system includes 'responsive programmes, educational programmes conducive to a critically constructive civil society, advancement of all forms of knowledge and scholarship, etc'. Although not explicitly articulated in the commission's goals, it can be deduced that in order to achieve these goals, the institutions have to come up with a suitable curricula which will turn these goals into a reality. From the onset, it became clear that there was 'a desire to steer South Africa along a high skills, high growth path of economic, cultural and social development which would lay a foundation of a new democratic society' (Ensor 2002:272). The NCHE report laid a foundation for the 1997 education White Paper three on higher education named A programme for the transformation of higher education.

The education White Paper of 1997 identified diverse social purposes of higher education which also have a bearing on the curricula and the type of graduates produced by the system. The White Paper for higher education (1997) was subsequently followed by the promulgation of the Higher Education Act of 1997 which first legalised the issue of mergers. In this Act, nothing is said about how the curricula of the merged institutions and subdivisions of institutions (e.g. faculties) should be composed. Maybe, as Jansen (2001:ix) puts it, 'people are beginning to question the fidelity logic assumed to exist between declaring policy and achieving it in everyday practice'. Thus each merged institution did as it deemed fit as it will be seen later in this discussion. ${ }^{3}$

After the second democratic elections in 1999, the newly elected second postapartheid Minister of Education, Prof Kadar Asmal, in his Call for action: mobilising citizens to build a South African education and training system for the 
21 st century (Department of Education 1999:5) joined the "change and transformation hub' and asserted that '[a]ll modern nations with strong democratic traditions and successful economies have invested heavily in the education and training of their people, in order to ensure access by all citizens to educational opportunity, and continuously raise the level and quality of learning throughout their societies'.

From the minister's words, once again an indirect referral to the quality of the curricula offered in the higher education institutions is put under the spotlight. It is in the same document that the minister for the first time referred to the issue of mergers by saying that 'higher education is likely to result in mergers between some institutions ..... 4

From 1999, some institutions began to merge as instructed by the Minister of Education and as it had been stated in the Higher Education Act of 1997. In the same year (1999), the minister approached the Council on Higher Education (CHE), his advisory statutory body 'to provide him with advice on the reconfiguration of the higher education system so that it could meet the highlevel human resource needs of the country' (Department of Education 2000:5). The CHE released a document called Towards a framework and strategy for reconfiguring the higher education system in South Africa and another one entitled Towards a new higher education landscape: meeting the equity, quality and social development imperatives of South Africa in the 21st century in 2000. In the latter document, the CHE task team (p. 12) indicated that the orientation and focus of higher education institutions (including the merged ones) would be on

- quality undergraduate programmes

- research related to curriculum, learning and teaching with a view to application

- comprehensive postgraduate taught and research programmes up to the doctoral level

- extensive research capabilities across a broad range of areas.

To continue the official rhetoric, the Minister of Education's foreword in the document entitled National plan for higher education (Department of Education 2001:2) purports that 'the National Plan provides us with a unique opportunity to establish a higher education system that can meet the challenges and grasp the opportunities presented to us by the contemporary world. We must be able to produce graduates with high quality skills and competencies in all fields.' The underlying implications of these words could be that in order for the institutions, especially the merged ones to achieve these goals, the curricula has to be tailored to suit and satisfy these goals.

The policy documents that steered the merging process are silent about what should happen to the curricula. As Ensor (2002:272) puts it, 'in policy deliberations on higher education from the early mid-1990s, little has been written specifically on higher education curricula'. The national plan for higher education 
(2001) document has a section on 'restructuring the institutional landscape of the higher education system' but nothing is said about what should happen to the curricula of the merged institutions. As a result, it looks like this issue is left to the merged institutions to decide what should happen in this case. As it will be seen in the following sections, the resultant curricula took a particular form - status quo, complete integration or partial compromise.

\section{MERGER CASE STUDIES ${ }^{5}$}

\section{Partial compromise scenarios}

This section involves the mergers between South African College of Teacher Education (SACTE) and the University of South Africa (UNISA); and the one between the University of Pretoria (UP) and the Medical University of Southern Africa (MEDUNSA) Faculties of Veterinary Science. In both cases, the partial compromise scenario is created by the fact that the resultant curricula after the merger includes courses and subjects from both institutions, although to varying degrees. For instance, SACTE lost most of its courses as compared to MEDUNSA.

The case of the merger between the South Africa College of Teacher Education (SACTE) and UNISA reflects a situation whereby UNISA lecturers accepted and used some of the colleges' material and courses. However, a lot of valuable material and personnel were lost during the merger. These two institutions are distance education institutions whose distinguishable feature is that students are not visible components of the stakeholder politics that shape the course and destiny of the incorporation. This is a university-college merger. In this merger, significant structural arrangements had been put in place to effect the potential merging of the curriculum of the two institutions. An external consultant had been employed to make the best use of the curriculum of the two. Curriculum committees have also been setup and a great deal of work had gone into mapping the curricula of the two institutions into each other. Despite these structural advantages, the objective of curriculum development did not materialise fully. The curriculum effects of the incorporation were perhaps the area in which some gains were made and simultaneously the greatest losses were incurred (Soobrayan 2002:34). The college's programmes were mapped onto the existing UNISA programmes and academic pathways were developed to facilitate the move of college students into the university. The South African Institute for Distance Education (SAIDE) facilitated the development of a programme leading to the National Professional Diploma in Education (NPDE) to be offered at UNISA. ${ }^{6}$ This was a gain for both UNISA, and the SACTE students since this would be a university qualification. Again, UNISA's Higher Diploma in Education (HDE - upgrading) consisted mainly of material taken from existing HDE programmes of SACTE and SACOL.

However, soliciting UNISA's staff to help prepare material for the NPDE was difficult, this diploma was mainly developed by the SACTE/SACOL staff since 
UNISA lecturers felt that they were already overloaded with their own work. ${ }^{7}$ The UNISA staff seemed less interested in the college's material, maybe due to the general perception that colleges are inferior to universities. This perception did have an influence in the curricular issues of this merger since some valuable college material and programmes were lost because the UNISA staff was not eager to even look at it. After the merger, the two institutions elected an Academic Programmes Sub-committee which recommended that SACTE's certificate courses be taken over by UNISA as their new programmes. Unfortunately, UNISA's staff members were not eager once again to take on these programmes and these programmes ended in 2002. There could be numerous reasons why the situation turned out as it did. Firstly, the UNISA staff felt that the incorporation had been a total mess, so they did not want to do anything with it. Secondly, there seemed to be no commitment to curriculum development on the part of UNISA and there was also a possible perception that the college material was inferior. As a result, no senior member of UNISA played a part in curricula development after the merger. The SACTE staff, however, eagerly participated in the Academic Programmes Sub-committee in an attempt to save some of their material and courses.

A further complication at the level of curriculum improvements was the reluctance on the part of UNISA lecturers to merge pedagogic imperatives with content requirements, particularly the elective courses in the NPDE and the UNISA Further Diploma in Education. For instance, the History department would teach a subject such as history with no co-operation between the Faculty of Education and its need for students to learn how to teach history. SAIDE had recommended specifically that SACTE certificate courses in Entrepreneurship, Human Rights and Healthy Lifestyles, Travel and Tourism, Reception Year and Computyping be incorporated into UNISA's Education Centre for Training and Development. This has not yet materialised.

As a result of this situation, where the curricula is a partial compromise with less college material used in the merged institution, and a lack of enthusiasm by UNISA lecturers, it is arguably crystal clear that planning for mergers needs to recognise that curriculum issues are not only about educational content, but also about the professional status, identity and self-image of the academics concerned. A further limitation was the power dynamics that subsumed the incorporation. Unfortunately, much of the potential curriculum from the college was not harnessed and was lost.

\section{Status quo scenario}

In this scenario, one or both of the institutions retain their curricula and continue with business as usual after the merger. In the University of Venda (UNIVEN) and Giyani College of Education (GCE) merger, the UNIVEN maintained the status quo by totally discarding the college's courses and material. Whereas in the 
University of the Witwaterrand (Wits) and Johannesburg College of Education (JTC) merger, both institutions continued with their various curricula.

The first scenario involves the merger between the JTC and Wits School of Education. This is a merger between a university and college. In this combination the JTC is a very strong college compared with the relatively weaker Wits faculty. Both institutions are historically white, located in an urban area and have a relatively stable financial base. Given the history of collaboration between these two institutions, it would be expected that the curriculum effects would not be that discernible (Sehoole 2002:72). But this was not to be the case. Firstly, rather than achieving complimentarity between the two schools owing to their past history of collaboration, there appeared to be a marked dissonance between the entities. The College of Education managed to secure the right to continue offering pre-service courses for primary and secondary school teachers, for which it claimed advanced and superior expertise to that of the School of Education from the university. Both the staff and students from the JCE were proud of their paradigmatic approaches towards teacher training in terms of which students are exposed to school experience from their first year.

Secondly, both institutions had previously offered the Bachelor of Primary Education (BprimEd) and also operated some teacher upgrading projects: the university through its Further Diploma in Education, and the college through a separate contractual agreement with the Gauteng Department of Education. Both institutions have maintained the status quo by continuing as if there has not been an official merger between them.

There is also a possibility of curriculum consolidation with the introduction of a generic undergraduate Bachelor of Education (BEd) programme. This will result in the phasing-out of all the other programmes. This new programme seems to have brought about some dichotomy among staff and further highlighted the paradigmatic differences among staff with regard to teacher training. The college staff claims some monopoly of expertise with regard to teacher training. This claim has been criticised by the university staff who believe that the college expertise was only relevant to the taught syllabus that was formerly prescribed by the national Department of Education. In the university context, college lecturers would be expected to develop their own curriculum and no longer rely on a prescribed syllabus.

The second scenario in which one of the partners did not change its curriculum involves the merger between the Giyani College of Education (GCE) and the University of Venda (UNIVEN) for Science and Technology in the Limpopo Province. This represents a combination of two rural residential institutions with severe financial disadvantages. Both institutions are historically black. The traditional GCE programmes consisted of a series of education diplomas which was developed on a strong consultative basis and moderated by Wits. The Venda university programmes consisted of a limited number of in-service teacher education diplomas, and a range of undergraduate and postgraduate degrees 
including a Doctor of Education. In this case, the university did not incorporate any aspect of the GCE curriculum nor programmes into their established curriculum for teacher education. A decision was taken that the end of 2002 would phase out the college's teacher education programmes. Since the merger, both the college curriculum and university curriculum are offered to respective students, with college students being referred to as pipeline students. In this scenario, the college curriculum was totally discarded; nothing from the college seemed to be of any value to the university. The university continued with business as usual as college lecturers scrambled to try and fit into the new system and new curriculum. So in this case, only the university maintained the status quo unlike the JTC and Wits merger in terms of which each one of them continued with their own curriculum.

\section{Complete integration}

In this section, two merger cases are discussed. These include the merger between the Faculties of Veterinary Science of UP and MEDUNSA; and the merger between Technikon Natal and ML Sultan Techikon. The resultant curricula in these two mergers reflect a contribution from both institutions, each one of them has contributed courses and materials to the new curricula.

The merger UP and MEDUNSA faculties veterinary science is a combination of only a sub-unit within two larger institutions. The former is historically white and financially advantaged, whilst the latter is historically black and financially disadvantaged. After the relocation of MEDUNSA students and staff in July 1999, both faculties had so-called 'pipeline students' who were taught using separate curricula from each faculty. MEDUNSA students remained registered with MEDUNSA and would receive the MEDUNSA qualification at the end of their studies. The same applied to the UP pipeline students. In order to avoid confusing students, it was decided that pipeline students should follow the old curriculum with the same lecturers from the respective faculties. The following pertinent observations can be made concerning the veterinary science curriculum of the two faculties:

- There has always been an overlap in the courses that were offered in both faculties. For instance, during the second year, courses such as Histology were taught in both institutions, Veterinary Public Health during the fourth year, and Pathology during the sixth year.

- Similar courses were offered at different years in the two faculties. For example, Veterinary Public Health was offered in the fifth and sixth years at MEDUNSA, while UP offered Public Health from the fourth to fifth years.

- Some courses, dealing with the same course content, had different names such as Veterinary Physiology at MEDUNSA and Applied Physiology and Pathophysiology at UP; Herd Health at UP is specified in terms of animal 
types such as cattle, pigs and small stock, whilst MEDUNSA refers to the same course as Herd Health I \& II, Poultry Science and Medicine at MEDUNSA (year V), and Poultry Diseases in UP (year IV).

It was noted that there was a perception that MEDUNSA catered for production animals such as cows, sheep, goats, poultry, while UP was understood to cater only for companion animals or pets. As a result of such criticisms, the developers of the new curriculum, which was done in collaboration with the two faculties, took great care in order to ensure that both types of animal services were well accommodated. The new dean of the merged faculty said that the faculty's main focus was to ensure that the curricula produced a graduate who could deliver both companion animal practice as well as production animal practice. Efforts were made to ensure that the new curriculum was completely integrated to reflect the single, merged institution.

The new curriculum contains courses and modules from both MEDUNSA and UP curricula, balancing the needs of veterinary science within different communities, and to make the qualification a versatile one in which all kinds of animals catered for. For some courses, the names have been changed. In some cases the content of the course stayed the same depending on the importance of such a course, while in other cases the content was added or decreased. From the third to fifth years of study, students start with six periods of 40 minutes each per week of 'junior clinics' in the Veterinary Academic hospital. This is part of their practical work.

The merged institution has clearly made commendable progress with its curriculum integration. But how do students experience the curriculum of the merged institution? Both MEDUNSA staff and students interviewed experience the curriculum as alien to their own academic and linguistic backgrounds; in their view, the curriculum privileges students from well-endowed former white schools - both the majority white as well as some of the black students who attended former white schools. One of the main reasons for these experiences of curriculum alienation among black students is the language problem. Previously, the MEDUNSA curriculum offered first-year students a course in English, which assisted black students from rural areas and poor schools to cope with the language demands of the veterinary programme. Such a facility no longer exists.

Related to this experience, is that one of the main concerns of MEDUNSA students and lecturers has been the apparent lack of understanding from the new faculty that black students are not from advantaged schools or advantaged families who use English on a daily basis. For this reason, black students continue to feel alienated and disadvantaged within the new curriculum.

The second scenario in which there was a partial compromise as far as the curriculum is concerned is in the case of the merger between the M L Sultan Technikon and Technikon Natal in the KwaZulu-Natal Province. It is also a crossracial merger with the former being historically designated for Indian South 
Africans and the latter for white South Africans. In this merger, facilitators from the PriceWaterhouseCoopers and two internal facilitators from each technikon and the Academic Sector Merger Task team helped in the curriculum establishment of the new institution. They prepared questionnaires in order to get an overview of all their academic programmes, identify the merger feasibility, benefits and opportunities; the workshops were also held as part of the exercise to inform the planning process. Prior to the merger, the curricula of the two technikons had numerous similarities in terms of the courses they offered, but there were some variations in their nature, design and delivery. Again, there were also some courses which were only offered by one institution, not the other. For instance, Technikon Natal offered Management, Child and Youth Development, Chiropractics, Radiography and others, whilst M L Sultan offered Biomedical Technology, Clinical Technology, Credit Management and others.

Furthermore, there were also some pockets of collaborative effort between some departments of the two institutions - mainly in the sharing of expertise and resources/facilities. For instance, for the National Diploma subject Chemical Engineering Technology III, Technikon Natal students were taught in the M L Sultan facilities, while at Bachelor of Technology level, Reactor Technology and Heat and Mass Transfer were taught jointly between the two institutions. The two institutions began to function as a merged entity in 2002. A number of departments began to merge their first year courses and co-taught similar subjects. There were problems raised by lecturers from both institutions - these reflected differences of epistemological and administrative nature. It was during this time that the issue of perceived academic excellence dominated discussions and debates. There is a belief that Technikon Natal offers superior quality education. One lecturer said that Technikon Natal maintains standards whilst the other technikon maintains pass rates. This issue of perceived seniority was not only concerned with academic standards, but it was also within the broad ambit regarding which of the two technikons was entering the merger as a senior partner. Fortunately, this perception did not cloud the eyes of the curricula planners in this merger. Both institutions had a fair share of their material included in the curricula.

\section{SYNTHESIS}

From the above discussion, it is clear that after a merger, institutions 'do as they please' regarding what happens to the curriculum. The outcome of what the curriculum will 'look like' in a merger can be compared to throwing a coin to the ground and not being sure of whether the outcome will be a head or tail. The legal implication for colleges in terms of the White Paper (1997) and the Higher Education Act, 1997 (Act 101 of 1997, section 21,2) was that colleges could either be established as autonomous institutions or as 'sub-divisions' that would be incorporated into an existing university or technikon. However, out of the four cases, the GCE/UNIVEN case presents the worst scenario in a merger whereby, 
neither programmes nor course material from the college was incorporated into the university curriculum. In this merger the college has not been regarded as a 'subdivision' as the law states it, since none of its diplomas and degrees was incorporated into the university's curriculum. Although both of these institutions are historically black institutions, the university had the upper hand in deciding what should be done with the curricula; hence there was an imbalance in terms of the power relations, with the university achieving a superiority status over the college. Since there is no policy document which maps out what should happen to the curricula after a merger, the incorporated colleges (SACTE and GCE) are at loggerheads as to what step to take to ensure that their programmes are considered in the merged institution. That is why Jansen (2001:ix) questions the fidelity logic assumed to exist between declaring policy and achieving it in everyday practice.

This college-versus-university inferiority mentality continues to be prominent once again in the SACTE/UNISA merger. The UNISA lecturers were not interested in the SACTE study material. As Soobrayan (2002:37) puts it 'the discrepancy in the attitudes of UNISA towards SACTE curriculum incorporation may be explained through the difference in the power relations between the two institutions. By this I do not mean that UNISA was in more powerful position (due to its university status) and therefore was uninterested. Instead UNISA felt threatened and potentially exposed by the very idea of incorporating material from a college into its own.'

UNISA staff felt that by incorporating college material into theirs would somehow imply that their material was not up to standard in some ways, especially because before the merger UNISA used to accredit the college's programmes. The partial compromise regarding the curriculum was all that SACTE stood to gain when some material was taken for the NPDE.

The last college merger scenario was that of JCE. Surprisingly, in this merger the college wielded the upper hand in terms of the curriculum incorporation. This time it was not the issue of superiority of the university that mattered, but the 'paradigmatic differences of the approaches' used for teacher training between the two institutions. The college staff boasted of the college's ability to train primary school teachers in a remarkable way and the fact that their students are exposed to school experience from first year. On the other hand, the university staff argued that 'the college used the syllabus prescribed by the Department of Education . . . hence their programmes were viewed as technicist rather than contributing towards generation of new knowledge as traditional academic work is supposed to do' (Sehoole 2002:73). In the midst of this tug of war, the college did not lose anything. Instead, a status quo situation remains between the two - both operating in-services courses alongside each other and recruiting students separately at the beginning of the year.

The issue of power relations is highlighted from a different point of view by the fact that some mergers were between institutions of the same status, that is, a university faculty (MEDUNSA) merged with another university faculty (UP), and 
a technikon (Technikon Natal) with a technikon (M L Sultan Technikon). In the MEDUNSA/UP case, the power relations issue was based on the fact that UP is a historically white institution with world-class facilities and an animal hospital worth millions. MEDUNSA could not help but become a junior partner in the merger with its animal hospital converted from a golf club house (Lethoko 2002:127). In other words, this was the incorporation of a weak (in terms of staffing, infrastructure and resources) historically black faculty into a strong historically white privileged faculty (Lethoko 2002:127). In any case, both institutions had very little to lose regarding the curriculum content. MEDUNSA lecturers as the 'inferior' partners were content with the complete integration of their courses. ${ }^{8}$ However, MEDUNSA experienced a culture shock and language alienation which resulted in curriculum alienation. These students were used to having a first-year English course which helped them to improve their study methods, language skills and others so that they could cope with the demands of veterinary training, especially because these black students were from disadvantaged backgrounds. As a result, it took them longer to grasp what was being taught because of the language deficiency and exotic facilities.

Parallel to this merger is the technikons' merger. 'The sheer momentum of apartheid and segregated institutions ...' (Chalufu 2002:151) determined the issue of power relations in this merger. Technikon Natal assumed superiority because it was a historically white institution, whilst M L Sultan was an Indian institution which was considered inferior to whites during the apartheid era. Technikon Natal claimed academic excellence over its partner, but this did not hamper the efforts to merge the curricula, although there were differences in terms of pedagogical and epistemological nature in the curriculum.

\section{CONCLUDING REMARKS}

In the document entitled Call to action, the Minister of Education points out, 'I was told by everyone that we have created a set of policies and laws in education and training that are at least equal to the best in the world.' But Lewin (2001:v) in his Foreword to the book entitled Implementing education policies: the South African experience has this to say, 'But many challenges remain, not least the growing realization that policy, however well founded must be translated into outcomes. Rhetoric is no substitute for addressing the realities that accompany meaningful policy-making; the need to build consensus, share ownership, allocate resources, clarify accountability and evaluate progress.' In my earlier discussion regarding the policies that influenced the merging process, it is clear that the government had the best intention ever, which is summarised in this statement articulated by the Minister in the National plan for higher education in South Africa (2001:2) 'The victory over the apartheid state in 1994 set policy-makers in all spheres of public life the mammoth task of overhauling the social, political, economic and cultural institutions of South Africa to bring them in line with the 
imperatives of a new democratic order'. It is very clear that these policies were meant to 'overhaul' the education system too. However, Sayed and Jonathan (2001:1) caution that 'for all the dazzle of post-apartheid education policies, there was considerable distance between policy (official statements of intent) and practice (experiences of teachers and learners in educational institutions)'.

In the case of the mergers used as examples in this article, the issues of power relations and power struggles clouded the merger process especially with regard to the curricula issue. None of the documents, which influenced, and advocated for, mergers gives guidelines on how the curricula should be composed after the merger. As a result 'the experiences of the teachers (lecturers in this case) and students' in the merged institutions are different from what the official statements of intent (policies) intended to achieve. To summarise the effects of these mergers, Jansen (2002:172) says that 'the impact of mergers on staff has . . . been devastating for the emotional and professional lives . . . careers ended abruptly or were suddenly redirected in ways that were traumatic to the affected staff'. In all the cases, student politics was not a determinant force in the origins, forms or outcomes of the mergers. Yet they are the ones for whom institutions exist. Without students there is no education and no teaching.

In conclusion, the curricula effects in the five case studies used in this article indicate that the government makes policies, but the government does not determine the outcomes. What happens in reality differs from what is written on a piece of paper.

\section{NOTES}

1 This article is a product of the study which was conducted by a group of five doctoral students (including the author of this article) at the University of Pretoria, South Africa. This study culminated in the publication of a book entitled Mergers in higher education: lessons learned in transitional contexts edited by Jansen, J D. 2002. Pretoria: UNISA Press.

2 In this article the word merger is used as a generic term to mean either a merger of two equal partners or an incorporation of a college into a university.

3 This article discusses the mergers between the South African College for Teacher Education and the University of South Africa; the Johannesburg College of Education and University of the Witwatersrand; Giyani College of Education and University of Venda; Veterinary Science Faculties of the University of Pretoria and the Medical University of the Southern Africa; and the M L Sultan Technikon and Technikon Natal.

4 See Chapter one of the book entitled Mergers in higher education: lessons learned in transition. The chapter traces and maps out the origins and the evolution of merger thinking in South Africa in detail.

5 The information used in this section has been taken directly from the chapters provided by the five doctoral students in the book that I have mentioned earlier.

6 This is a new national interim education diploma specifically designed for under qualified teachers.

7 The South African College for Open Learning (SACOL) had earlier on merged with SACTE, so staff from both institutions worked on this diploma. 
8 See the staff and student effect of this merger in the book entitled Mergers in higher education: lessons learned in transitional contexts. Pp 123-125.

\section{BIBLIOGRAPHY}

Chalufu, S. 2002. The merger of KwaZulu-Natal technikons, in Jansen, J D, ed. Mergers in higher education: lessons learned in transitional contexts. Pretoria: UNISA Press.

Council on Higher Education (CHE). 2000. Towards a new higher education landscape: meeting equity, quality and social development imperatives of South Africa in the 21st century. Pretoria.

Department of Education. 1997a. Education White Paper 3: A programme for the transformation of higher education. (Notice 1196 of 1997). Pretoria.

—. 1997b. Higher Education Act of 1997. Pretoria. Government Gazette (18515).

- 1999. Call to action: Mobilisisng citizens to build a South African education and training system for the 21st century. Pretoria. 27 July.

- 2001. The restructuring of the higher education system in South Africa-Report of the National Working Group to the Minister of Education. Pretoria. December.

Ensor, P. 2002. Curriculum, in Transformation in higher education: global pressures and local realities in South Africa. Cape Town: UCT Press.

Jansen, J D. 2001. Questioning fidelity in policy making: research stories across fields of educational inquiry. Perspectives in Education 19(3): Editorial introduction.

Jansen, J D, ed. 2002. Mergers in higher education: lessons learned in transitional contexts. Pretoria. UNISA Press.

Lethoko, M. 2002. The merging of veterinary science faculties, in Jansen, J D (ed) Mergers in higher education: lessons learned in transitional contexts. Pretoria: UNISA Press.

Ministry of Education. 2001. National Plan for Higher Education. Pretoria, South Africa. February.

National Commission on Higher Education (NCHE). 1996. A framework for transformation. Cape Town. NCHE.

Sayed, Y and Jansen, J, eds. 2001. Implementing education policies: the South African experience. Cape Town: UCT Press.

Sehoole, T C. 2002. The incorporation of the Johannesburg College of Education into the University of Witwatersrand, in Jansen, J D (ed) Mergers in higher education: lessons learned in transitional contexts. Pretoria: UNISA Press.

Soobrayan, V. 2002. The incorporation of the South African College of Teacher Education into the University of South Africa, in Jansen, J D, ed. Mergers in higher education: lessons learned in transitional contexts. Pretoria: UNISA Press. 